\title{
Geleceğin Sağlık Profesyonellerinde İnternet Bağımlılığının Yaşam Kaliteleri Üzerine Etkisi
}

Effect of Internet Addiction on Life Quality of Future Healthcare Professionals

\author{
Nilgün ULUTAŞDEMIR ${ }^{1}$, Esra VERIMM ${ }^{2}$, Emine BAKIR ${ }^{1}$, Esma DENIZ ${ }^{3}$ \\ 1. Kent Konseyi, Gaziantep \\ 2. Gaziantep Üniversitesi Sağlık Bilimleri Fakültesi, Gaziantep \\ 3. Özel Akademi Hastanesi, Gaziantep
}

\section{$\ddot{O Z E T}$}

Amaç: Bu araştırma geleceğin sağllk profesyonellerinde internet bağımlılı̆̆ının yaşam kaliteleri üzerine etkisini değerlendirmesi amacıyla planlanmıştır.

Gereç ve Yöntemler: Tanımlayıcı tipte olan çalışmanın evrenini Ocak 2015 'te özel bir üniversitenin sağllk bölümlerini okuyan öğrencileri (296 kişi) oluşturmuştur. Anketin uygulandı̆̆ sırada okulda olan ve çalışmaya katılmayı kabul eden 286 öğrenci örnekleme alınmıştır. Araştırmanın verileri; sosyo-demografik özellikler ve internet kullanımını etkileyen faktörler ile Internet Bağımlılık Ölçeği (İBÖ) sorularından oluşan anketin uygulanmasıyla toplanmıştır. Verilerin analizi t testi, tek yönlü varyans ve korelasyon analizleri kullanılarak yapılmıştır.

Bulgular: Araştırmaya kapsamına alınan öğrencilerin \%61.9'u $k u z$ ve yaș ortalamaları $19.97 \pm 1.03$ 'd $t$ r. Öğrencilerin \%22.1'I haftada 20 saat ve üzeri internet kullanmaktadir. Araştırmaya kapsamına alınan öğrencilerin IBÖ puan ortalamast $30.77 \pm 15.70$ 'dir.

Sonuç: Sağlık profesyonelleri ortalama internet kullanıcısıdır. Anahtar Kelimeler: internet; sağlık profesyonelleri; yaşam kalitesi
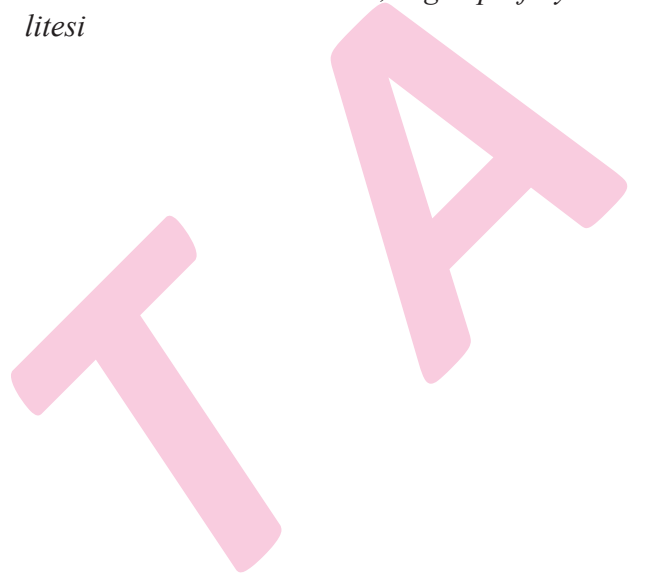

İletişim Bilgileri

Sorumlu Yazar: Dr. Nilgün ULUTAŞDEMIR

Yazışma Adresi: Kent Konseyi, Gaziantep

E-posta: nulutasdemir@yahoo.com

Tel: +90 (530) 6965959 iş̧: +90 (462) 3355000 Dahili: 3125

Makale Geliş Tarihi: 12.12.2016

Makale Kabul Tarihi: 14.03.2017

DOI: http://dx.doi.org/10.16948/??????

\section{ABSTRACT}

Objective: This study, It is planned for purposes to assess the impact of internet addiction onto life quality of future health professionals.

Material and Methods: Students studying for a private university department of health (296 people) created the universe of descriptive study of the type in January 2015. In the surveyed, 286 students who in school and agreed to participate in the study has been sampling. The research data; was collected with the implementation of the survey consists of Internet Addiction Scale (IAS) questions with socio-demographic characteristics and factors affecting internet usage. Data analysis was performed using t-test, single direction variance and correlation analysis.

Results: Students covered in the survey, $61.9 \%$ were female students and the mean age was 19.97 $\pm 1.03 .22 .1 \%$ of students uses internet 20 hours or more per week. Within the scope of the research students' IAS point average was $30.77 \pm 15.70$.

Conclusion: The health professionals are average internet user.

Keywords: internet; health professionals; quality of life 


\section{GIIRIŞ}

"İnternet bağımlılı̆̆ı" kavramını ilk kez Goldberg 1995 yılında kullanmıştır. İnternet bağımlılığı DSM-IV' teki alkol bağımlılığ1 tanı ölçütleri doğrultusunda tanımlanmıştır [1]. Ancak "İnternet Bağımlılığı Hastalığı" kavramını ilk gündeme getiren uzmanlardan biri Young'dır [2]. İnternet bağımlılı̆g 1 , internetle ilgili aşırı zihinsel meşguliyetin olması, internet dişında geçirilen vaktin değersiz bulunması, doyum sağlamak için gittikçe artan miktarda internet kullanımı, internette planladığından daha fazla kalmak, yoksunluğunda sinirlilik, gerginlik hissetmek ve aşırı internet kullanımının iş, sosyal ve aile hayatında olumsuz etkilere neden olabilmesi şeklinde tanımlanmaktadır [3, 4].

Türkiye İstatistik Kurumu'nun 2012 Y11 Hanehalkı Bilişim Teknolojileri Kullanımı Araştırması sonuçlarına göre bilgisayar ve internet kullanım oranının en yüksek olduğu yaş grubu 16-24'tür [5]. İnternet bağımlılığının özellikle uzak doğuda ve diğer ülkelerde üniversite öğrencileri için yeni ve ciddi bir ruh sağlığı sorunu olduğu bildirilmektedir [6]. İnternet bağımlılığında herhangi bir bağımlılık sendromunda görülen yoksunluk semptomları (sinirlilik, ajitasyon, agresyon), artmış tolerans, kendine hakim olamama (aşırı kullanım), negatif pekiştirme (yalan söyleme, sosyal izolasyon) bulgularının hemen hepsi görülebilmektedir [7].

Sağlığı geliştirmeye yönelik yaklaşımların ön plana çıkmasıyla yaşam kalitesi kavramı da sağlik hizmetlerinin önemli bir hedefi haline gelmiştir [8]. Uzun yıllar ruhsal bozukluklar ve özellikle anksiyete bozukluklarının yaşam kalitesine etkisi göz ardı edilmiş ve sadece semptomlardaki düzelme dikkate alınmıştır. Son y1llarda yaşam kalitesi kavramının ön plana çıkmasıyla birlikte bu konuyla ilgili çalışmaların arttığı ve sosyal fobinin de yaşam kalitesi üzerine olumsuz etkilere sahip olduğu görülmüştür [9].

Sağlıklı olmak her insanın temel hakkı olup, bunun sağlanması ve sürdürülmesi sağlık personelinin temel amacı olduğu kadar, kişinin de kendi sorumluluğudur. Kişinin sağlığı geliştirici davranışları kazanması için, kendini kontrol etmesi, bu davranışları kazanmak için istek duyması gerekir. Çünkü sağlığı geliştirmek için olumlu sağlık davranışının kazandırılması ve sürdürülmesi gerekir. $\mathrm{Bu}$ nedenle üniversite öğrencilerinin sağlık davranışları incelenmesi ve eksik oldukları konularda desteklenmesi toplum sağlığı açısından önemlidir [10]. İnternet bağımlılığının son dönemlerde ortaya çıkan yeni tanımlanmış bir sorun olarak görülmesi, bu alanda çalışan klinisyenler tarafından yeterince bilinmemekte ve sıklıkla gözden kaçabilmektedir. Özellikle gençler arasında gün geçtikçe artan sayıda olgularla karşılaşmamız nedeniyle internet bağımlılığını daha iyi tanımak ve yaygınlığını belirlemek bu anlamda önemlidir. Üniversite öğrencilerin yaşam biçimleri yaşam kalitesini etkilemektedir. Bu araştırma, geleceğin sağlık profesyonellerinde internet bağıml1lığının yaşam kaliteleri üzerine etkisini değerlendirmek amaciyla planlanmıştır.

\section{GEREÇ ve YÖNTEM}

Tanımlayıcı tipte olan çalışmanın evrenini Ocak 2015'te Özel Bir Üniversitenin Sağlik Bilimleri Fakültesi ve Tıp Fakültesi öğrencileri (296 kişi) oluşturmuştur. Anketin uygulandığ sırada okulda olan ve çalışmaya katılmayı kabul eden 286 öğrenci örnekleme alınmıştır. Çalışma için etik kurul onayı ve kurum izni alınmıştır.

Araștırmanın verileri; sosyo-demografik özellikler ve internet kullanımını etkileyen faktörler ile İnternet Bağımlılık Ölçeği (İBÖ) sorularından oluşan anketin direkt gözlem altında uygulanmasıyla toplanmıştır. Young (1998) tarafından geliştirilen "İnternet Bağımlılığı Testi” 20 maddeden oluşmaktadır. Test sonucunda 20 ile 100 arasında bir puan alınmaktadır ve alınan puanlar doğrultusunda 20-49 puan arası "ortalama internet kullanıcısı", 50-79 puan aras1 "ara sira problemli internet kullanımına sahip", ve 80-100 puan arası ise "sık s1k problemli internet kullanımına sahip" olarak nitelenmektedir. Testen alınan yüksek puanlar yüksek problemli internet kullanımını ifade etmektedir [11].

Ölçek, Balta Çakır ve Horzum tarafından 2006 yılında Türkçe'ye uyarlanmıştır. Üniversite öğrencileri üzerinde yapılan çalışmanın Cronbach alpha testi ile hesaplanan iç tutarlık katsayısı 0.895 olarak bulunmuştur. Beşli likert tarzı bir ölçek olan İnternet Bağımlılık Testi'nde katılımcilardan "nadiren", "ara sira", "siklıkla", "çok zaman" ve "herzaman" seçeneklerinden birini işaretlemesi istenmektedir. Bu seçeneklere sirasiyla 1, 2, 3, 4 ve 5 puan verilmektedir.

Balta Çakır ve Horzum'un (2006) geçerlilik ve güvenirlik çalışmaları sonucunda 10 . madde ölçekten çıkarılarak 19 soru sorulmuştur. Sonuçta 19 maddelik üç alt faktörlü geçerliği ve güvenirliği olan bir ölçek elde edilmiştir. Katılımc1lar ölçekten en az "19", en fazla "95" puan alabilmektedir [12]. Verilerin analizi t testi, tek yönlü varyans (ANOVA) ve korelasyon analizleri kullanılarak yapılmıştır. 


\section{BULGULAR}

Araștırmaya kapsamına alınan öğrencilerin \%61.9’u kız (177 kişi), \%38.1'i erkek öğrenci (109 kişi) olup, yaş ortalamaları $19.97 \pm 1.03$ $(\min =18, \max =25)^{\prime}$ 'dır. Araştırmaya katılan öğrencilerin \%32.2'si T1p, \%24.1'i Beslenme ve Diyetetik, \%22.7'si Hemșirelik ve \%21.0'1 Fizik Tedavi ve Rehabilitasyon bölümü öğrencisidir. Araştırmaya kapsamına alınan öğrencilerin İBÖ puan ortalamas1 $30.77 \pm 15.70$ 'dir. Öğrencilerin İBÖ puanlarına göre dağılımı incelendiğinde; \%1.1'i 80 puan ve üstü (internet bağımlisı=̇̇B), \%10.8' ̈̈ 50-79 puan (riskli internet kullanıcısı=RİK) ve \% 88.1'i 49 puan ve altı (ortalama internet kullanıcısı=OİK)'dır. Öğrencilerin sosyodemografik özelliklerine göre İBÖ puanlarının dağılımı Tablo 1'de gösterilmiştir.

Tablo 1: Öğrencilerin sosyodemografik özelliklerine göre IBÖ puanlarının dağııımı.

\begin{tabular}{|c|c|c|c|c|}
\hline Sosyodemografik Özellikleri & n & Min & Max & івÖ (Mean士SD) \\
\hline \multicolumn{5}{|l|}{ Cinsiyet } \\
\hline Kadın & 109 & 1 & 85 & $28.21 \pm 14.26$ \\
\hline Erkek & 177 & 5 & 81 & $34.92 \pm 17.06$ \\
\hline $\mathrm{p}$ değeri & & & & $0.002^{*}$ \\
\hline \multicolumn{5}{|l|}{ Yaş } \\
\hline 18 yaş & 12 & 11 & 85 & $41.50 \pm 24.32$ \\
\hline 19 yaş & 80 & 1 & 62 & $29.52 \pm 13.75$ \\
\hline 20 yaş & 123 & 4 & 79 & $29.50 \pm 14.84$ \\
\hline 21 yaş & 54 & 4 & 81 & $31.40 \pm 17.62$ \\
\hline 22 yaş & 12 & 8 & 51 & $37.00 \pm 13.10$ \\
\hline 23 yaş & 3 & 14 & 57 & $38.00 \pm 21.93$ \\
\hline 24 yaş & 2 & 17 & 41 & $29.00 \pm 16.97$ \\
\hline p değeri & 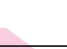 & & & $0.001^{*}$ \\
\hline \multicolumn{5}{|l|}{ Bölüm } \\
\hline Tıр & 92 & 7 & 79 & $30.76 \pm 15.87$ \\
\hline Hemşirelik & 65 & 8 & 65 & $28.20 \pm 14.02$ \\
\hline $\begin{array}{l}\text { Fizik Tedavi ve Rehabili- } \\
\text { tasyon }\end{array}$ & 60 & 5 & 81 & $34.58 \pm 15.98$ \\
\hline Beslenme ve Diyetetik & 69 & 1 & 85 & $29.89 \pm 16.42$ \\
\hline $\mathrm{p}$ değeri & & & & 0.093 \\
\hline \multicolumn{5}{|l|}{ Aile Tipi } \\
\hline Çekirdek Aile & 237 & 1 & 85 & $30.06 \pm 15.62$ \\
\hline Geniş Aile & 38 & 12 & 79 & $34.18 \pm 16.51$ \\
\hline Parçalanmış Aile & 11 & 8 & 59 & $34.18 \pm 13.83$ \\
\hline $\mathrm{p}$ değeri & & & & 0.928 \\
\hline \multicolumn{5}{|l|}{ İkamet Edilen Yer } \\
\hline Yurtta & 114 & 4 & 81 & $29.78 \pm 16.44$ \\
\hline Aile ile & 101 & 1 & 75 & $29.90 \pm 14.70$ \\
\hline Arkadaş ile & 71 & 4 & 85 & $33.86 \pm 15.82$ \\
\hline $\mathrm{p}$ değeri & & & & 0.588 \\
\hline \multicolumn{5}{|c|}{ Kendi Sosyoekonomik Düzeyini Algılama } \\
\hline Alt (düşük) & 16 & 8 & 65 & $37.43 \pm 19.98$ \\
\hline Orta & 215 & 1 & 75 & $28.78 \pm 13.51$ \\
\hline Üst (yüksek) & 55 & 7 & 85 & $36.61 \pm 20.07$ \\
\hline p değeri & & & & $0.000^{*}$ \\
\hline
\end{tabular}

Erkek öğrenciler kız öğrencilere göre daha fazla internet bağımlısıdır $(p=0.002)$. Sosyoekonomik düzey artıkça öğrencilerin internet kullanım bağımlılı̆̆ artmaktadır $(\mathrm{p}=0.000)$. Araştırma kapsamındaki 19-21 yaş grubu öğrencilerde internet bağımlılığ1 görülmesi diğer yaş gruplarına göre daha fazladır $(\mathrm{p}=0.001)$. Öğrencilerin bölümlere göre İBÖ alt bileşenlerine ait dağılımları Tablo 2'de gösterilmiştir.

Tablo 2: Öğrencilerin bölümlere göre ïÖ alt bileşenlerine ait puanlarının dağııımı.

\begin{tabular}{|l|c|c|c|}
\hline Bölüm & $\begin{array}{c}\text { оí } \\
\mathrm{n} \%\end{array}$ & $\begin{array}{c}\text { Rik } \\
\mathrm{n} \%\end{array}$ & $\begin{array}{c}\text { ї } \\
\mathrm{n} \%\end{array}$ \\
\hline Tıр & 7726.92 & 155.24 & 00.00 \\
\hline Hemşirelik & 6020.97 & 51.74 & 00.00 \\
\hline $\begin{array}{l}\text { Fizik Tedavi } \\
\text { ve Rehabilitasyon }\end{array}$ & 5117.83 & 82.79 & 10.34 \\
\hline Beslenme ve Diyetetik & 6422.37 & 31.02 & 20.69 \\
\hline
\end{tabular}

İnternet kullanım bağımlılığı alt bileşenleri ile sağlık bölümleri arasında anlamsal bir ilişki bulunamamıștır $(\mathrm{p}=0.093)$. Öğrencilerin $\% 22.1$ 'i (64 kişi) haftada 20 saat ve üzeri internet kullandığını ifade etmiştir. Ödevlerini en çok internet üzerinden yapan öğrenci oranı $\% 83.6$ 'dir.

Öğrencilerin interneti kullanım alanlarında ilk sirada video izleme (\%37.8) ve ikinci sirada sohbet etme (\%30.4) yer almıştır. Cinsiyet ile internet kullanım alanları arasında anlamlı bir iliş̧ki bulunamamıştır $(\mathrm{p}>0.05)$. Öğrencilerin İBÖ alt bileşenlerine ait puan ortalamalarının dağılımları Tablo 3 'te gösterilmiştir.

Tablo 3: Öğrencilerin iBÖ alt bileşenlerine ait puan ortalamalarının dağılımı.
\begin{tabular}{|l|c|c|}
\hline \multicolumn{1}{|c|}{ іBÖ Alt Bileşenleri (n=286) } & Mean \pm SD & (Min-Max) \\
\hline OіK & $26.66 \pm 11.21$ & $(0-49)$ \\
\hline Rí & $59.03 \pm 6.62$ & $(50-79)$ \\
\hline ї & $83.66 \pm 2.30$ & $(80-85)$ \\
\hline
\end{tabular}

Öğrencilerin yaşam kalitelerini etkileyen faktörler değerlendirildiğinde; kendi sağlik durumunu kötü algilayan $(p=0.010)$, düzenli beslenemeyen $(\mathrm{p}=0.010)$ dinlenmeye zaman ayıramayan $(p=0.003)$, hobisi olmayan $(p=0.033)$, sigara kullanan $(p=0.023)$, alkol kullanan $(p=0.004)$ öğrencilerin internet bağımlılığ 1 daha yüksektir.

Araştırmaya kapsamına alınan sağlık profesyonelleri, ortalama internet kullanicis1 (\%88.1)'dir. Dinlenmeye zaman ayıramama ile internet bağımlılı̆g 1 arasında pozitif bir ilişki saptanmıştır $(p=0.001, r=0.196)$. Sigara kullanma ile internet bağımlılığı arasında pozitif bir ilişki saptanmıştır $(\mathrm{p}=0.030, \mathrm{r}=0.128)$. 


\section{TARTIŞMA}

Araştırmada erkek öğrencilerin kız öğrencilere göre daha fazla internet bağımlılığ yaşadıkları bulunmuştur. Bulgumuz ile literatürde benzerlik gösteren çalışmalar mevcuttur [13-17]. Ancak yapılan bazı çalışmalarda internet bağımlılığ görülme sıklığ 1 ile cinsiyetler arasında fark bulunmamıştır [18-21]. Genel olarak kızların daha çok e-mail ve sosyal ilișki kurma amaciyla, erkeklerin ise oyun oynama, haber okuma, chat, yeni insanlarla tanışma, illegal materyallere ulașma, müzik ve program indirme amaciyla internete bağlanmayı tercih etmelerinden kaynaklanabilir.

Araştırma kapsamındaki 19-21 yaş grubu öğrencilerde internet bağımlılığı görülmesi diğer yaş gruplarına göre daha fazladır. Greefield'in (1999) yaptığ 1 çalışmada ise internet bağımlılığı ile yaş arasında anlamlı bir ilişki saptanmamıștır [22]. 2011 yılı Nisan ayı içerisinde gerçekleştirilen Hane halkı Bilişim Teknolojileri Kullanım Araştırmasına göre internet ve bilgisayar kullanımının en s1k 16-24 yaş grubunda olduğu saptanmıştır [23]. İnternet kullanım bağımlılığ 1 alt bileşenleri ile sağlık bölümleri arasında anlamsal bir ilișki bulunamamıştır $(p=0.093)$.

Araştırmaya katılan üniversite öğrencilerinden internet bağımlısı olanlar haftada 40 saat internet kullandığını, bağımlı olmayanlar ise haftada 1 saat internet kullandığını ifade etmiştir. Young'ın (1996) yaptığ 1 çalışmasında bu rakamlar sirasiyla 38.5 saat ve 4.9 saat saptanırken, Hardie ve Tee'nin yaptıkları çalıșmasinda ise 68.8 saat ve 21.8 saat olarak saptanmıștır [24, 25]. Haftalık internet kullanım süresi ile internet bağımlılığı arasında pozitif bir ilişki saptanmıştır $(p=0.000, r=0.728)$. İnternette uzun süre vakit geçirmenin internet bağımlılığında beklenen bir sonuç olarak görülebilir. Araştırmada sosyoekonomik düzey artıkça öğrencilerin internet kullanım bağımlılı̆̆ artmaktadır $(\mathrm{p}=0.000)$. Bayraktar ve Gün'ün (2007) yaptıkları çalışmada internetin çoğunlukla üst sosyo-ekonomik düzeydeki kişiler tarafından kullanıldığ 1 ve sosyo-ekonomik düzey arttıkça internet kullanımının da arttığ 1 bulunmuştur [26]. Bizim bulgumuzun aksine sosyoekonomik düzey ile internet bağımlılığı arasında anlamsız olmadığını bulan çalışmalar vardır [27-29]. Sosyoekonomik gücün internette zaman geçirmeyi arttığ 1 ve internete erişimi kolaylaştırdığı söylenebilir.

Araştırma kapsamına alınan öğrencilerin interneti kullanım alanlarında ilk sırada video izleme (\%37.8) ve ikinci sirada sohbet etme
(\%30.4) yer almıștır. Öğrencilerin cinsiyeti ile internet kullanım alanları arasında anlamlı bir ilişki bulunamamıştır ( $\mathrm{p}>0.05)$. Bizim bulgumuzun aksine Fortson, Scotti, Cihen, Malone, Kevin (2007) yaptıkları çalışmada erkek ve kızların farklı nedenlerle internet kullandıkları vurgulanmaktadır [30]. İnterneti kullanma tercihleri cinsiyetler arasında etkili olmadığ 1 düşünebilir. Hobisi olmayan öğrencilerin $(p=0.033)$ ve dinlenmeye zaman ayıramayan ögrencilerin $(p=0.003)$ internet bağımlılığ 1 daha yüksektir. Yine dinlenmeye zaman ayıramama ile internet bağımlılığı arasında pozitif bir ilişki saptanmıştır ( $\mathrm{p}=0.001, \mathrm{r}=0.196) . \mathrm{Bu}$ bulgularımızın aksine internet kullanımın sosyal yaşantıya etki etmediğini saptayan çalışmalar mevcuttur $[31,32]$. İnternetin başında zaman geçiren öğrenciler sosyal yaşantıya zaman ayırmada zorlanabilir dolayısıyla yaşam kaliteleri düşebilir. Sosyal yaşantıya zaman ayırma ile internet bağımlılığ 1 feedback etki gösterebilir.

Araştırmamızda sigara ve alkol kullanan öğrencilerin internet bağımlılığı daha yüksek bulunmuştur. Yine sigara kullanma ile internet bağımlılığı arasında pozitif bir ilişki saptanmıştır $(p=0.030, r=0.128)$. Araştırmamız bulguları ile uyumlu olarak yapılan çalıșmalarda da madde kullanımın internet bağımlılığ ile ilişkili olduğu saptanmıştır [6, 33-38]. Bu bulgular 1şı̆̆ında aşırı internet kullanımının, alkol ve sigara bağımlılığına neden olabileceği söylenebilir. Araştırmaya katılan öğrenciler ortalama internet kullanıcısı (\%88.1)'dır. Ergin, Uzun ve Bozkurt (2013) Tip Fakültesi öğrencileri üzerinde yaptığ 1 araștırmada, riskli ve bağımlı internet kullanım oranını düşük bulmuştur [33].

Bayraktar ve Gün (2007) yaptıkları çalışmada internet kullanım oranın $1 \% 1$ olarak saptarken, Niemz, Griffiths, Banyard (2005) \%18, Young (1996) ise \%80 olarak saptamıştır [26, 34]. Unniversite öğrencilerin internet kullanmaları yaşam kalitelerini orta düzeyde etkilediği söylenebilir.

\section{SONUÇ ve ÖNERILER}

Sonuç olarak bu araştırmada geleceğin sağlık profesyonelleri ortalama internet kullanıcisıdır. Dinlenmeye zaman ayıramayan, hobisi olmayan, sigara ve alkol kullanan üniversite öğrencilerin internet bağımlılığı daha yüksektir. $\mathrm{Bu}$ tür araştırmalar doğrultusunda öğrencilerin internet bağımlığ 1 düzeylerini azaltıc1, okul toplumunun sağlı̆̆ını ve yaşam kalitelerini artırıcı etkenlere yönelik müdahale ve iyileştirici çalışmalar planlanması düşünülebilir. 


\section{KA $\boldsymbol{A} \boldsymbol{N} \boldsymbol{A} \boldsymbol{K} L \boldsymbol{A} R$}

1. Özcan NK, Buzlu S. Problemli Internet Kullanımını Belirlemede Yardımcı Bir Araç: Internette Bilişsel Durum Ölçeğinin Üniversite Ögrencilerinde Geçerlik ve Güvenirliği. Bağımlılık Dergisi 2005;6:19-26.

2. Young K. What Makes the Internet Addictive: Potential Explanations for Pathological Internet Use. Paper Presented at the 105th Annual Conference of the American Psychological Association August 15, 1997, Chicago, IL. http://www.netaddiction. com/article/babitforming.htm (Erişim tarihi:24.05.2015).

3. Arısoy Ö. Internet Bă̆ımlılı̆̆g. Türkiye Klinikleri Dergisi 2009;21:75-83.

4. Young KS. Internet Addiction. Am Behav Sci 2004;48:402-44.

5. Türkiye İstatistik Kurumu (TÜIK). 2012 Yllı Hanehalkı Bilișim Teknolojileri Kullanımı Araștırmast. 16/08/2012 Sayı: 10880 http://www.tuik.gov.tr/PreHaberBultenleri.do? $i d=10880$ (Erişim tarihi:24.05. 2015).

6. Kandell JJ. Internet Addiction on Campus: The Vulnerability of College Students. Cyberpsychol Behav 1998;1:11-17.

7. Young KS. Internet Addiction: The Emergence of A New Clinical Disorder. Cyberpsychology and Behaviour 1996;1:237-44.

8. Şahin B. Sağlı̆̆ın Ölçümü ve Kullanım Alanlarına Teorik Bir Baklş. Sağllk ve Toplum 1999;9(8):3-10.

9. Gültekin BK, Dereboy F. Üniversite Öğrencilerinde Sosyal Fobinin Yaygınlığl ve Sosyal Fobinin Yasam Kalitesi, Akademik Başarl ve Kimlik Oluşumu Üzerine Etkileri. Türk Psikiyatri Dergisi 2011;22(3):150-8.

10. Ilhan N, Batmaz M, Akhan LU. Üniversite Öğrencilerinin Sağlıklı Yaşam Biçimi Davranışları. Maltepe Üniversitesi Hemşirelik Bilim ve Sanatı Dergisi 2010;3(3):34-44.

11. Young K. Caught in the Net: How To Recognize The Signs of Internet Addiction and A Winning Strategy For Recovery. John Wiley, New York. http://www.netaddiction.com/articles/babitforming.htm (Erişim tarihi:24.05.2015).

12. Çakır Balta Ö, Horzum MB. Internet Bağımlılık Testi. Eğitim Bilimleri ve Uygulama 2008;7(13):87-102.

13. Johansson A, Gotestam K. Internet Addiction: Characteristics of A Questionnaire and Prevalence in Norwegian Youth (1218 years). Scand J Psychol 2004;45:223-9.

14. Morahan-Martin J, Schumacher P. Incidence and Correlates of Pathological. Internet Use among College Students. Comp Human Behav 2000;16:13-29.

15. Chou C, Condron L, Belland JC. A Review of The Research on Internet Addiction. Educational Psychology Review 2005;17(4):363-88.

16. Scherer K. College Life On-Line: Healthy and Unhealthy Internet Use. JCSD 1997;38:655-65.

17. Yen JY, Yen CF, Chen CS, Tang TC, Ko CH. The Association between Adult ADHD Symptoms and Internet Addiction among College Students:The Gender Difference.Cyberpsychol Beha 2009;12(2):187-91.

18. Kim K, Ryu E, Chon MY, Yeun EJ, Choi SY, Seo JS, Nam $B W$. Internet Addiction in Korean Adolescents and Its Relation To Depression and Suicidal Ideation: A Questionnaire Survey. International Journal of Nursing Studies 2006;43:185-92.

19. Kaltiala-Heino R, Lintonen T, Rimpela A. Internet Addiction? Potentially Problematic Use of The Internet in a Population Of 12-18 Year-Old Adolescents. Addict Res Theory 2004:12:89-96.
20. Jang KS, Hwang SY, Chois JY. Internet Addiction and Psychiatric Symptoms among Korean Adolescents. Journal of School Health 2008; 78:165-71.

21. Pawlak, C. Correlates of Internet Use and Addiction in Adolescents. Dissertation Abstracts International Section A: Humanities \& Social Sciences 2002;63(5-A):1727.

22. Greenfield DN. Psychological Characteristics of Compulsive Internet Use: A Preliminary Analysis. Cyberpsychol Behav 1999;2:403-12.

23. 2011 Yllı Hanehalkı Bilişsim Teknolojileri Kullanım Araştırması Sonuçları. T.C. Başbakanlık Türkiye İstatistik Kurumu Haber Bülteni 18 Ağustos 2011, sayl:170.

24. Young KS. Internet addiction: The Emergence of A New Clinical Disorder. Cyberpsychology and Behaviour 1996; 1:237-44.

25. Hardie E, Tee MY. Excessive Internet Use: The Role Of Personality, Loneliness and Social Support Networks In Internet Addiction. Australian Journal of Emerging Technologies and Society 2007;5(1):34-47.

26. Bayraktar F, Gün Z. Incidence and Correlates of Internet Usage among Adolescents in North Cyprus. Cyber-psychol Behav 2007;10(2):191-7.

27. Yoo HJ, Cho SC, Ha J, Yune SK, Kim SJ, Hwang J, Chung A, Sung YH, Lyoo IK. Attention Deficit Hyperactivity Symptoms and Internet Addiction. Psychiatry Clin Neurosci 2004;58:48794.

28. Park SK, Kim JY, Cho CB. Prevalence of Internet Addiction and Correlations With Family Factors among South Korean Adolescents. Adolescence 2008;43(172):895-909.

29. Balta ÖÇ, Horzum MB. Web Tabanlı Öğretim Ortamındaki Öğrencilerin Internet Bă̆ımlılı̆̆ııı Etkileyen Faktörler. Ankara Üniversitesi Eğitim Bilimleri Fakültesi Dergisi 2008;41(1):187205.

30. Fortson BL, Scotti JR, Cihen Yu-C, Malone Judith DB, Kevin $S$. Internet Use, Abuse and Dependence among Students at A Southeastern Regional University. Journal of American College Health 2007:56:2.

31. Oğuz B, Zayim N, Özel D, Saka O. Tip Öğrencilerinin Bilissel Durumları. Akademik Bilișim. Çanakkale Onsekiz Mart Universitesi, 30 Ocak-01 Şubat 2008.

32. Ersun A, Köze B, Muslu G, Beytut D, Başbakkal Z, Conk Z. Hemşirelik Yüksekokulu Ögrencilerinde Internet Kullanımı Ile Sosyal Destek Sistemi Arasindaki İliskinin İncelenmesi. İ.Ü.F.N. Hemşirelik Dergisi 2012;20(2):86-92.

33. Ergin A, Uzun Su, Bozkurt Aİ. Tip Fakültesi Öğrencilerinde Internet Băğlmlılı̆̆ Siklı̆gl ve Etkileyen Etmenler. Pamukkale Tip Dergisi 2013;6(3):134-42.

34. Niemz K, Griffiths M, Banyard P. Prevalence of Patho-Logical Internet Use among University Students and Corre-Lations With Self-Esteem, The General Health Questionnaire (GHQ) and Disinhibition. Cyberpsychol Behav 2005;8:562-73.

35. Young KS. Internet Addiction: The Emergence of A New Clinical Disorder. Paper Presented at 104th Annual Meeting of the American Psychological Association Toronto, Canada: 10 A $\breve{g}$ ustos 1996.

36. Greenberg JL, Lewis SE, Dodd DK. Overlapping Addictions and Self Esteem Among College Men and Women. Addiction Behaviour 1999;24:565-71.

37. Bai YM, Lin CC, Chen JY. Internet Addiction Disorder among Clients of A Virtual Clinic. Psychiatr Serv 2001;52(10):1397.

38. Goudriaan AE, Oosterlaan J, Beurs E, Vanden BW. Pathological Gambling: A Comprehensive Review of Biobehavioral Findings. Neurosci Biobehav Rev 2004;28:123-41. 